\title{
Emergence of Energy Services Ecosystems: Scenario Method as a Policy Enabler
}

\author{
Argyro Almpanopoulou ${ }^{1 *}$, Jukka-Pekka Bergman ${ }^{1}$, Tero Ahonen ${ }^{2}$, Kirsimarja Blomqvist, \\ Paavo Ritala ${ }^{1}$, Samuli Honkapuro ${ }^{2}$, Jero Ahola ${ }^{2}$ \\ ${ }^{1}$ School of Business and Management, Lappeenranta University of Technology, Finland; \\ *School of Business and Management, Lappeenranta University of Technology; P.O Box 20, \\ Lappeenranta, Finland \\ ${ }^{2}$ School of Energy Systems, Lappeenranta University of Technology, Finland \\ argyro.almpanopoulou@lut.fi, Jukka-Pekka.Bergman@lut.fi, \\ Tero.Ahonen@lut.fi, Kirsimarja.Blomqvistelut.fi, \\ Paavo.Ritala@lut.fi, Samuli.Honkapuro@lut.fi, Jero.Ahola@lut.fi
}

\begin{abstract}
The very nature of the energy sector, as a highly regulated and capitalintensive sector, as well as the challenges imposed by the global transition to renewable energy, have made the emergence of innovation ecosystems, which are necessary for the development and commercialization of new solutions, rather challenging. We examine the emergence of energy services ecosystems from a policy perspective, suggesting the scenario method as an enabler for focusing the attention of relevant actors and identifying triggering events that guide their activities toward a shared future. We illustrate our arguments using three case examples from Finnish public policy. Our study contributes to the nascent literature of ecosystem emergence and public innovation policy in the field of energy services.
\end{abstract}

Keywords: Ecosystem, innovation, emergence, energy services, scenario method, research policy.

\section{Introduction}

The literature on business and innovation ecosystems has been accumulating for over two decades, beginning with the seminal contribution by Moore (1993). The ecosystem concept has since attracted significant attention, especially within the body of practitioner and managerial literature, which has largely focused on how ecosystems can be managed around focal actors, technologies, or platforms (e.g. Iansiti and Levien, 2004; Iyer and Davenport, 2008; Rohrbeck et al., 2009; Williamson and De Meyer, 2012). Furthermore, research on innovation ecosystems has concentrated on how actors organize into systems around new developments, technologies, and ideas (e.g. Autio and Thomas, 2013; Ritala et al., 2013). One important question that is still rather untapped relates to how innovation and business ecosystems emerge: that is, how actors begin to organize themselves around interdependent ecosystems with shared goals, visions, and purposes. While self-organizing is a key attribute of business ecosystems (Peltoniemi, 2006), policy interventions are often helpful 
when ecosystems are being built around new technologies and innovations (Clarysse et al., 2014).

To better understand how ecosystem emergence can be facilitated, in this paper, we focus on how public policy initiatives enable the emergence of ecosystems around energy sector innovations. Existing literature has begun to study, for example, the role of public funding and knowledge in enabling ecosystem emergence (Clarysse et al., 2014). In the fields of renewable energy and energy services, facilitating the emergence of new business ecosystems is an especially relevant public policy context. While the literature on energy policy has identified the importance of public policy initiatives (e.g. Lewis and Wiser, 2007; Lund, 2007), there is still not sufficient evidence of the particular mechanisms that enable participants to focus their attention and cognition toward mutually shared goals and future development paths. In this paper, we suggest that scenario methods can function as public policy intervention mechanisms for enabling and facilitating the emergence of a new energy service ecosystem.

We frame our arguments within a hierarchy of systems, including both the broader national innovation system and the business and innovation ecosystems that emerge with (and without) the influence of the national innovation system. For example, the national innovation system consists of universities, research centers, large and small firms, and various legal and regulatory institutions. By the term energy services ecosystem, we refer to an innovation ecosystem consisting of both private and public actors interacting in various innovation- and business-related activities. In this sense, we build upon a recent conceptualization of innovation ecosystems as "clusters (physical or virtual) of innovation activities around specific themes (e.g., biotechnology, electronics, pharmaceutical and software)" (Ritala et al., 2013, p.248).

Our paper uses several case illustrations from Finland to understand ecosystem emergence in the energy services sector. The energy sector in Finland (and worldwide) is a highly regulated and capital-intensive sector, which makes the "natural" emergence of new energy services ecosystems rather challenging. Thus, we argue that, especially in this context, the Finnish innovation system can play an important role as an enabler for the emergence of new energy services ecosystems. We specifically concentrate on policy interventions and related scenario work as mechanisms that facilitate the emergence of new ecosystems, including, in our case, the energy services ecosystem. We argue that the scenario method and related processes focus the attention of various ecosystem actors, while also supporting the triggering events that guide future development. To support our argumentation, we examine three cases of different research programs financed by TEKES (the national agency for innovation development) and Academy of Finland innovation system strategic initiatives.

Recent literature has focused on the transformation from loosely coupled research and development collaborations to more determined business and innovation ecosystems (Möller and Rajala, 2007; Aarikka-Stenroos and Sandberg, 2012; Clarysse et al., 2014).

Another stream of literature has examined how ecosystems are built and how they emerge 
in the first place (e.g. Moore, 1993; Ritala et al., 2013). Our study contributes to these streams of literature from a public policy intervention perspective, as we suggest that the scenario method and related processes can play an important role in the emergence of new innovation ecosystems. With this paper, we aspire to initiate discussion and inspire future studies on the impact of policy intervention on the emergence of innovation ecosystems: a phenomenon that is little studied. We argue that the potential of the innovation ecosystem may not be fully realized without such mechanisms as the scenario process. Using our case examples, we illustrate how potential knowledge and resources are mobilized for new ecosystem emergence, how the relevant stakeholders can create shared understandings of the future, and what kinds of triggering mechanisms can encourage passive actors to actively engage, take risks, and commit.

Our paper is organized as follows: We begin with a brief discussion of the emergence of ecosystems, followed by a brief description of the role of scenario methods for focusing and triggering this emergence. Next, we present three illustrative public policy cases in the field of energy services, focusing in particular on the attitudes, cognitions, decisions, and actions of relevant actors participating in the scenario method and related processes.

\section{Understanding the emergence of ecosystems}

The innovation ecosystem, as a concept, has been used to describe the increasing emphasis on the interdependency and co-evolution of individual actors (Autio and Thomas, 2013), such as suppliers, customers, governments, and universities. A seminal contribution to the literature of ecosystems in the business and innovation context was made by James Moore (1993), who adopted the biological metaphor of the "ecosystem" to describe how organizations and individuals interact and evolve in systems that operate very similarly to those that we can observe in nature. The key insights, which were later developed by other authors, were built on the systemic nature of ecosystems, including the principles of shared environment, co-evolution, interdependence, and ecosystem leadership (e.g. Moore, 1993; Iansiti and Levien, 2004). Recently, the scope of the term "ecosystem" has expanded significantly to include platform ecosystems (e.g. Thomas et al., 2014), technology ecosystems (e.g. Wareham et al., 2014), and service ecosystems (e.g. Akaka et al., 2013).

The birth and evolution of ecosystems has been one of key topics ever since the seminal contribution by Moore (1993), who established the concept of the ecosystem life cycle, which consists of steps of birth, expansion, leadership, self-renewal, and decline/death. However, the main focus of ecosystem literature has been on explaining or solving issues faced by the focal actor or the ecosystem leader (e.g. Iansiti and Levien, 2004). Specifically, prior literature has widely studied how focal actors operate in ecosystems and how they create and organize them by imposing rules for other actors. Empirical investigations of large, incumbent companies and their already established ecosystems have represented the main approach in much of the extant ecosystem research (e.g. Iyer and Davenport, 2008; Isckia, 2009; Rohrbeck et al., 2009). 
Prior literature either implicitly or explicitly grants significant power to the focal actor in designing the innovation ecosystem, neglecting the roles and influence of other, non-focal (e.g. entrepreneurial) actors within the ecosystems they inhabit (e.g., Ozcan and Eisenhardt, 2009; Hallen and Eisenhardt, 2009). As stated earlier empirically, the innovation ecosystem literature has largely studied innovation ecosystems organized around a technological platform (e.g., Gawer and Cusumano, 2014; Wareham et al., 2014) or a single focal actor (e.g., Leten et al., 2013), assuming that this focal actor can direct the future of the ecosystem as a whole. However, this approach is rather myopic, since the key to the emergence of innovation ecosystems is the connection between micro and macro behaviors and the cooperative and competitive interactions among individual actors (Smith and Stacey, 1997; Peltoniemi, 2006). Namely, emergence refers to the phenomenon through which individual actors' motives and actions lead to unpredictable population-level behavior (Peltoniemi, 2006). In other words, emergence occurs as a result of dynamic interactions and coevolutions among individual actors that lead to unanticipated outcomes, such as the rise of larger entities (e.g. innovation ecosystems that exhibit properties possessed by none of the systems' actors) (Holland, 1997; Midgley, 2008). Simply put, the whole is larger than the sum of its parts. Further, when the link between action and long-term outcome is lost in the interactions between the actors and the system, it is impossible for an external actor or powerful member of the system to control or design the system's behavior. Instead, the behavior emerges (as described by Smith and Stacey, 1997, p.83).

In innovation ecosystems, unlike in biological ecosystems, selection forces are not unknown to those experiencing them; instead, they involve learning and deliberate efforts by purposive actors to influence their environment (Garnsey and Leong, 2008; Garnsey et al., 2008). Therefore, Garnsey and Leong (2008) argue that actors can deliberately transform their environments, including the very selection forces that act upon them. This indicates the scope for proactive decision making and motivated action (cf. Penrose, 1995, p.3). In fact, we argue that investors and policy makers, as members of the wider innovation ecosystem, are in a position to influence the emergence and methods of operation of the forces of selection (see Garnsey and Leong, 2008; Clarysse et al., 2014). For example, through well-informed financial and networking support, these individuals are able to enable the emergence of the innovation ecosystems necessary to support the commercialization of emerging technologies (Garnsey and Leong, 2008). However, as Clarysse et al. (2014) show, policy makers' support for research programs seeking knowledge creation does not automatically trigger the emergence of innovation ecosystems, since the value creation processes of innovation ecosystems are significantly different, implying that policies to support innovation ecosystems must be specifically tailored.

The energy services ecosystem can be viewed as a complex system (see Cilliers, 2001) which is subject to constant inflows and outflows and which evolves over time. The system consists of actors, activities, and processes that are interdependent. The ecosystem evolves through changes in the actors themselves, as well as collective, system-level co-evolutions stemming from internal and external influences. During the process of emergence, the relevant actors appear and begin to conduct activities that are (at least partially) 
interdependent from those of other actors. The actors also begin to coordinate their activities, with each taking a different role in the ecosystem (Moore, 1993; Iansiti and Levien, 2004). In order for innovation ecosystems (as social structures) to be sustained, there must be interactions among actors that are sufficiently recurrent and personal to create shared understandings, legitimations, and relations of acknowledged interdependence (Giddens, 1984).

We view the role of the knowledge and shared cognition of ecosystem actors as an important precondition for emergence. We argue that one key benefit of the emergence of innovation ecosystems is the production and combination of knowledge necessary for innovation, which is dispersed among different, previously unconnected actors. Thus, an innovation ecosystem can be viewed as an integrating mechanism that allows for both knowledge exploration and knowledge exploitation (Valkokari, 2015) and that enables its actors to jointly address complex problems (Leten et al., 2013). Furthermore, we claim that innovation system-level policy tools and mechanisms can make such knowledge visible and provide opportunities for the actors who are potentially forming an ecosystem to create a shared vision and agenda. In particular, we focus on the scenario method as an intentional process that can focus the attention of ecosystem actors, enable the necessary social interaction, and facilitate a shared cognition over triggering events that guide actors towards a shared and plausible future. In the following section, we discuss the role of the scenario method as an enabler of ecosystem emergence.

\section{Scenario method as an enabler of ecosystem emergence}

Scenarios are means to affect future development. The fundamental idea behind the scenario approach is to provide a structured way to create a dynamic and ongoing social interaction among individuals and to expand people's thinking (Wack, 1985a; Wack, 1985b; Schoemaker, 1995; Schwartz, 1996). Scenarios express the vision and aims of a certain group of stakeholders. They help organizations and individuals develop and broaden the strategic thinking on possible future realities and facilitate an understanding of the fundamental drivers of business, market, and technological trends and changes (Masini and Vasquez, 2003; Wack, 1985b). Scenarios describe the complexity of phenomena that cannot be formally modelled (Schoemaker, 1997). Scenario processes make it possible to assess the competitive landscape in a new light, revealing alternative future development paths (Godet, 2000; Schoemaker, 1997). In the process of strategy-making, the scenario method has been used to create a holistic understanding of complex environments to focus actors' operations towards a desired future (Schoemaker, 1993; Schoemaker, 1995). The use of scenarios reflects an organization's proactive orientation (Godet, 2000), enhancing its organizational flexibility to respond to environmental uncertainty and future actions. The scenario method can provide a structured approach for dynamic and ongoing interactions among organizations to create intentional strategic conversations and dialectic processes (Schwartz, 1996). 
The scenario process is established when there is a need for influencing the development of an organization or wider business environment (Wack, 1985a; Wack, 1985b), such as, in our case, energy service ecosystems. Since, from a certain stakeholder point of view, scenarios are intentional, they seek to produce new knowledge and focus the performance of participating organizations. This scenario process can be set by a single organization or political decision makers to influence public and business organizations' decision making (Schwartz, 1996). Scenario networks vary from intra-organizational working groups to inter-organizational virtual networks, where individuals have access to a wider knowledge base, connections become more interactive, and more holistic interpretations are formed.

For the purposes of this study, we view the scenario method as an enabler of ecosystem emergence, which takes place through 1) focusing the attention of ecosystem actors towards a certain direction, 2) enabling social interactions, and 3) making visible the triggering events that have a strong effect on the perceived futures of ecosystem actors. Scenario methods enable such focusing processes and the subsequent discovery of triggering events, which, together, help to facilitate ecosystem emergence when relevant actors are involved and influenced by the scenario work.

First, scenarios are means to focus and communicate strategic intent with the organization and the wider stakeholder network. Second, as a structured process, it has been seen as an effective management tool facilitating social interaction in a networked context to explore the environment in order to understand complexity or recognize alternative paths to the most desired goal (de Jouvenel, 2000; Roubelat, 2000; Bergman et al., 2006). Therefore, the scenario process serves as a catalyst for channeling organizational resources towards new opportunities and goals. In other words, the scenario process works as a facilitated and structured context by enabling a group of individuals to serve as intermediaries (or interfaces) in interactions between the internal and external environments and by amalgamating them into a network to work on the same task under a shared vision (van der Heijden, 2002).

Third, scenario processes can trigger the involved actors' activities, thus leading them to address and develop resources towards shared goals. When there is a goal of affecting the development of industry or society, the shared vision is developed among the most influential stakeholders and disseminated to the wider stakeholder network to trigger the desired actions. Scenarios are descriptions of the most desired development paths toward these commonly accepted goals. They may provide new business opportunities or even trigger large-scale industry-level renwal.

Fig. 1 summarizes the role of scenario methods as policy tools in enabling ecosystem emergence by focusing actors' attention, discovering important triggering events that guide these actions, and identifying plausible scenarios that can be shared among ecosystem actors. 


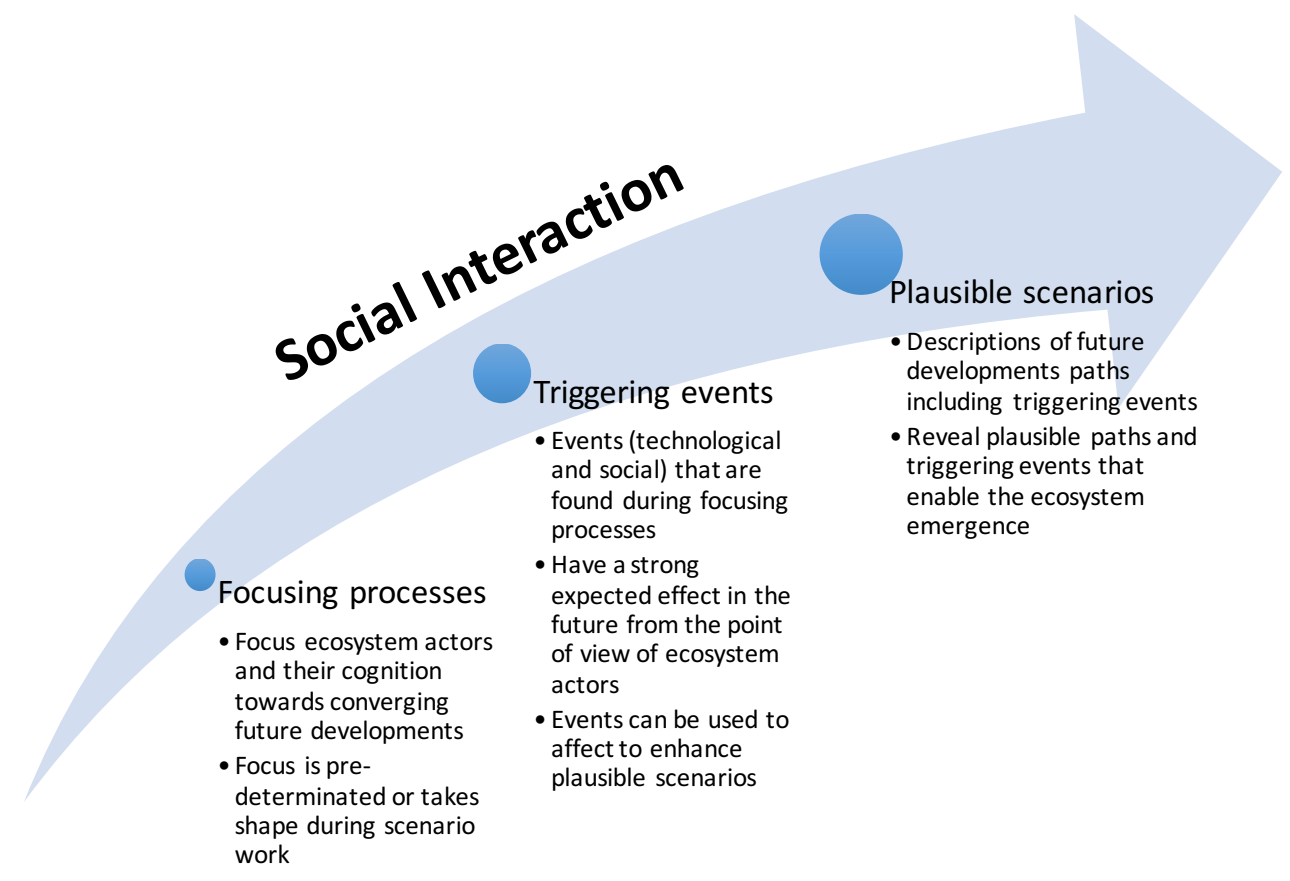

Fig. 1. Process for the scenario work.

\section{Emergence of energy service ecosystems research in Finland}

Emerging ecosystems in the field of sustainable energy production, energy efficiency, and new services represent one of the feasible areas for scenario use methods. Since the energy sector is currently a subject of political and financial interest in Finland, the topics mentioned above are prominently visible in research programs funded by the Academy of Finland and TEKES (the Finnish Funding Agency for Innovation). These are the two most important state-owned financiers for research and innovation in the Finnish innovation system, and their objective is to create renewal and growth. These programs are introduced here to clarify the background of the three illustrative cases studied in following sections.

In order to foster industrial renewal, political decision makers have recently enforced structural and financial changes within the Finnish innovation system. One of these policy making instruments has been the launching of strategic research initiatives for political decision making and (radical) industrial renewal. As a result of these changes, a new financing body, the Strategic Research Council (SRC) at the Academy of Finland, was established to provide funding for long-term and program-based research aimed at finding solutions to the major challenges facing Finnish society. The most important objectives of 
selected SRC programs are to provide support for evidence-based policy; to develop solutions for the regeneration of Finnish society; and to propose ideas for the future of business, industry, and working life. In 2015, the SRC launched programs related to the energy transition in Finnish society (SET) and the disruption of digital technologies in industry, including in the energy sector $(D D I)$ have started. In addition, the Academysponsored project "Change in Business Ecosystems for Local Renewable Energy and Energy Efficiency-Better Energy Services for Consumers (USE)" applies the idea of business ecosystems to a context that extends actor networks from businesses to consumers and public actors.

TEKES strategic research openings are projects seeking to achieve breakthroughs, create new high-level competences, and develop significant new areas of growth in Finland, all in pursuit of a larger goal of fostering the renewal of the Finnish economy. TEKES points out that these projects must have high levels of novelty, including truly new perspectives or unique combinations of topics, and that they need to have the potential to create significant and lasting change in Finnish economy. Furthermore, the visions of these projects must be simultaneously feasible, concrete, and challenging, since the projects will create competences that can be used to achieve goals that may initially seem impossible. The NeoCarbon Energy project is one of the TEKES strategic research openings. Its objective is to establish a perspective on the needs, business opportunities, and societal implications of an emission-free energy system; to study the connections between the electricity grid and large-scale seasonal energy storage; and to explore its integration with other energy sectors (Landowski, 2014).

One of the recognized key factors in the emergence of energy ecosystems is digitalization, which supports the transformation of an energy system from a centralized system to a more distributed one. This energy transformation is especially visible in Germany, the leading EU country in terms of its use of photovoltaic solar energy systems due to its Energiewende policy (Pegels and Lütkenhorst, 2014; International Energy Agency, 2015). These two factors will provide opportunities for new service development, industry renewal, and, thus, new businesses, which are being studied, with the help of scenario methods, in Academy (SET and DDI) and TEKES-funded projects (Neo-Carbon). These business models can change dramatically as the role of the customer transforms from that of a "consumer" to that of a "prosumer" (Pagani and Aiello, 2010).

For example, in the consumer energy sector, digitalization is now visible through the use of Automatic Meter Readings (AMRs), which allow the remote monitoring of customer energy consumption with one-hour resolution; the use of Nord Pool spot price-based tariffs; and the development of services related to these options. AMRs can be considered physical components of smart grids, providing means for the automated control of active resources, including distributed generation, energy storage, and demand response (DR), which refers to flexibility in energy consumption (Koivisto et al., 2015). A promising service-based example of demand response applications is that of electric heating systems, which may alter their operation according to a given price or frequency signal to allow a required DR to be fulfilled without harm to the end user (There, 2015). AMR also provides technical 
infrastructure for other third-party energy services, thus motivating the efficient use of energy and the active management of electric power quality (Logenthiran et al., 2012). -

\section{Case projects and the role of the scenario method}

Scenario methods are currently applied in three different research projects within the energy sector (see Fig. 2). Of these, TEKES-funded Neo-Carbon Energy first launched with publicly available scenarios in 2014. Academy of Finland-funded projects Smart Energy Transition (SET) and Digital Disruption of Industry (DDI) followed in October 2015. This section introduces each project and its scenario work.

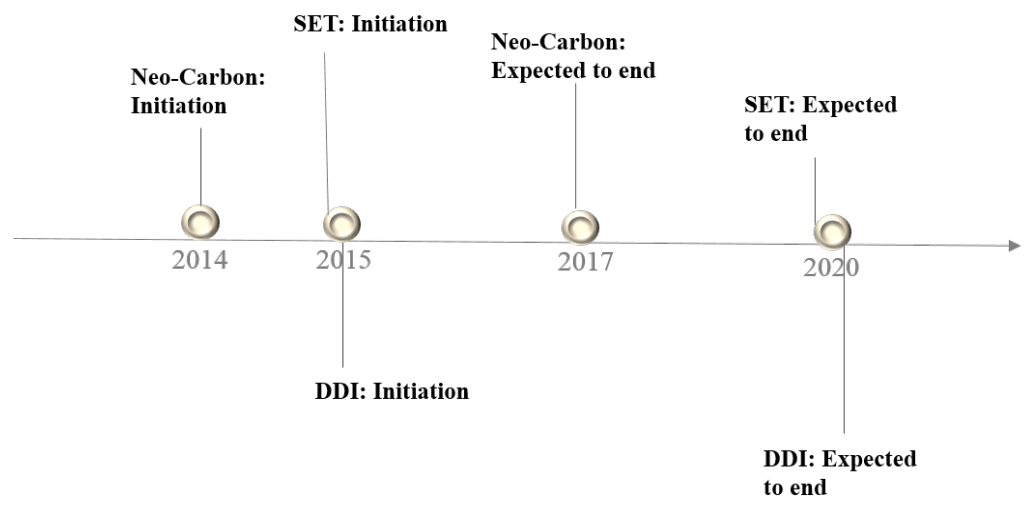

Fig. 2. Timeline of the three projects.

\subsection{Neo-Carbon Energy: Scenarios through Futures Cliniques}

The Neo-Carbon energy project seeks to design the operation principles and key components of a renewable energy system based solely on wind, solar, and sustainable hydro and biomass. Since the main challenge in solar and wind power is the intermittency of their generation, the key focus lies in seasonal storage solutions and solutions enabling the bridging of the electric power system with other energy systems, such as gas networks, transportation fuels, heat networks, industrial chemicals, etc. The main proposed solution for the energy storage problem is the power-to-gas $(\mathrm{P} 2 \mathrm{G})$ process, through which synthetic natural gas, $\mathrm{SNG}$ (i.e. methane), is produced from $\mathrm{CO}_{2}$ and $\mathrm{H}_{2}$ during times of excess solar and wind production. The natural gas infrastructure provides nearly infinite storage capacity for chemical energy, and the $\mathrm{P} 2 \mathrm{G}$ solution can integrate the different energy systems (heat, power, and transportation).

The aim of the Neo-Carbon Energy project scenarios is to recognize possible radically different energy futures with novel technology solutions and to identify what kinds of businesses these solutions can create. One key question involves how to present the Neo- 
Carbon Energy system as attractive to citizens.

In Neo-Carbon, there are four future scenarios for the year 2050 (illustrated in Fig. 3), all of which are transformative. In all scenarios, the world has undergone a third industrial revolution (see Rifkin, 2011), which includes revolutions in both energy production and communication technologies. In each scenario, energy is produced according to the NeoCarbon energy model; however, the implementation of this solution, as well as people's lifestyles, values, cultures, and business concepts, vary from scenario to scenario (Heinonen et al., 2015).

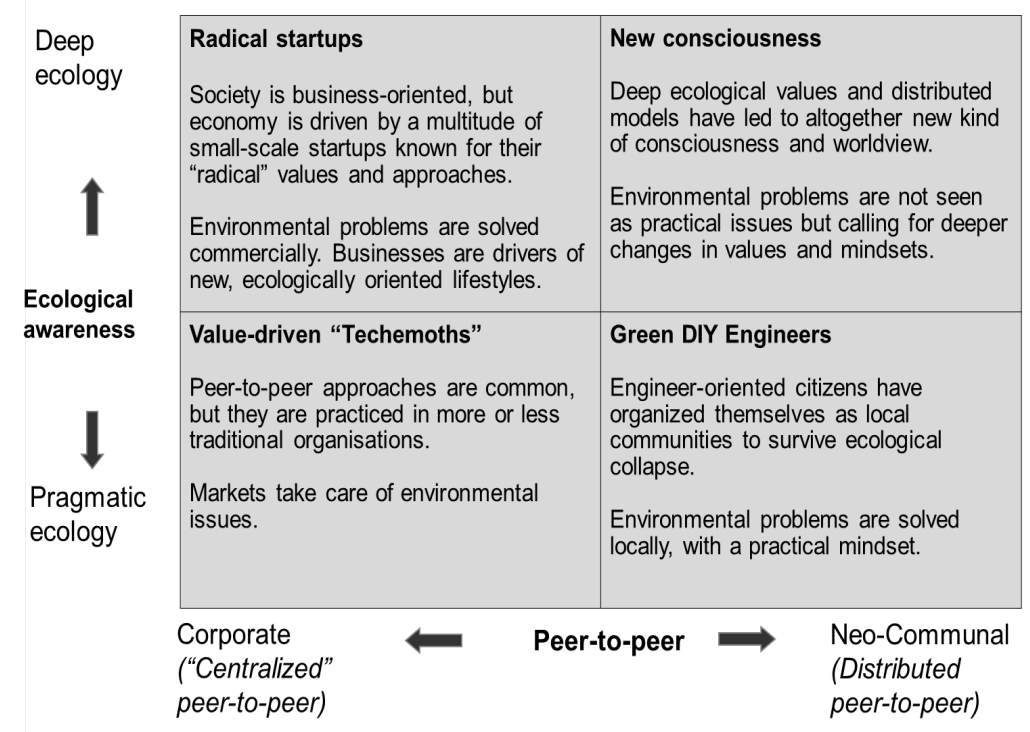

Fig. 3. Four transformative scenarios in the Neo-Carbon Energy project (Heinonen et al., 2015)

Tentative scenarios have been tested in the Futures Clinique (a participatory and exploratory future workshop, which is designed to anticipate especially radical futures and surprising effects [i.e. black swans]; see Heinonen and Ruotsalainen, 2013), during which participants (e.g. project members, government, business, and third sector representatives) work around a variety of scenario sketches. One of the challenges in employing such transformative scenarios, which involve varying socio-cultural aspects, seems to be that they might be overly abstract for primarily technology-oriented experts. However, since these experts were involved in the scenario processing in the Futures Clinique, they were, at least to some extent, committed to the ideas presented. Nevertheless, there is still work to be done to strengthen the links between these future scenarios and technical and economic-oriented research work.

The Neo-Carbon energy project provides benefits for Finnish industry by introducing a novel energy system to leading industrial partners, educating decision makers, supporting 
corporate-level strategy development, and identifying concrete business cases. Finally, the project designs and builds prototypes of the selected key technical devices, which the system requires in order to work. During the project, key companies can identify their roles within the energy system value chain and decide how they will subsequently invest in the subject. Ultimately, the project lays the foundations for a novel energy system and enables Finland to lead the transition toward this type of energy system, thus turning it into a business opportunity.

The project's research work is carried out by a multidisciplinary research team from the VTT Technical Research Centre of Finland, Lappeenranta University of Technology and the University of Turku Finland Futures Research Centre. The advisory board comprises industrial partners and provides internal pitching for the project by quarter-annually reviewing the outcomes of the project and directing its work.

\subsection{Smart Energy Transition (SET)}

Disruptive technologies have been defined as advances that will transform life, business, and, ultimately, the global economy (Manyika et al., 2013). Renewable energy production and storage technologies are potentially disruptive technologies because they change not only the way we produce energy, but also the way we use energy, do business with energy, and innovate. Therefore, smart energy solutions can cascade into new business ecosystems, leading to radical shifts in the roles of producers, service providers, and consumers. The Smart Energy Transition project was launched in October 2015, and analyzes the ongoing global transition and its impacts on Finnish society, including, in particular, the potential benefits for cleantech, digitalization, and the bioeconomy.

The SET consortium consists of seven Finnish universities and research institutes and four other organizations involved in researching and actively facilitating a sustainable smart energy transition in Finland. The work of these actors is divided into six work packages (see Fig. 4), whose progress is advised and accelerated by three expert panels and a transition arena for the demonstration of obtained results. 


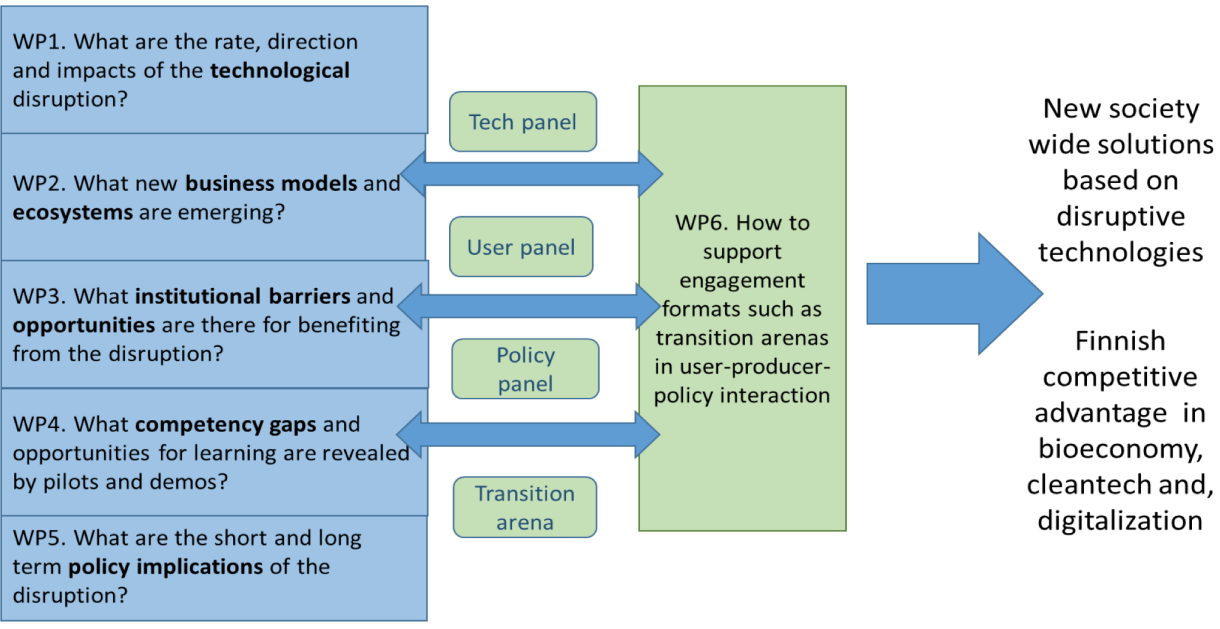

Fig. 4. Description of work packages in the SET project (SET, 2015).

Scenario work is needed in the SET project to clarify the possibilities revealed by disruptions in the energy sector. Compared to the more generic scenario work done in the Neo-Carbon Energy project program, the scenario work in the SET project begins by providing an overall perspective on available solutions to produce, store, and consume renewables-based electrical energy through literature reviews and workshops. Hence, the focus is first on technical aspects. However, once these aspects have been explored and first alternative scenarios are constructed, policies, society, etc. will be considered. Based on the literature review and existing Neo-Carbon scenarios, two alternative scenarios for the year 2030 will be drafted. These will be publicly introduced in workshops and modified according to the results of the Delphi query, which is used to provide input about triggering events related to these scenarios.

\subsection{Digital Disruption of Industry (DDI)}

The focus of the Digital Disruption of Industry project is on the economic and social implications of this disruption. The DDI project studies how the underlying fabric of current industries - how they operate, how they organize themselves, how they reason about their business and partners, and how they strategize-will be contested when novel digital (institutional) infrastructures with their own rules, norms, and mindsets begin to take form. The project focuses on several sectors of industry from an institutional perspective, which facilitates an evaluation of changes both in the national context and from a broader comparative perspective. The DDI project will yield a comprehensive study of the impact of digitalization, not only to industry itself, but also to its ecosystem partners, its stakeholders, and, more widely, its relevant societal institutions, such as business practices and models, regulation, management, and governance. 
The DDI consortium consists of five Finnish universities and research institutes: Aalto, VTT Technical Research Centre of Finland, Lappeenranta University of Technology, ETLA and the University of Turku. This group collaborates with several organizations (large industry, small- and medium-sized enterprises (SMEs), startups and innovators, RTDI actors, government bodies, employees, customers, and consumers) in the targeted industrial and ICT ecosystems. These different actors collaborate in the planning, execution, and assessment of specific interventions related to concrete cases of digital disruption, the challenges involved, and the impacts on stakeholders. Further, within the consortium, there is close interaction with regard to information sharing, interactions with other stakeholders, roadmaps and scenarios, joint publications, events, and action plans for managing the disruption.

The DDI is divided into five research work areas, which simultaneously tackle the two overall objectives of the project: the research objective of synthesizing an increasingly expressive scientific understanding of digital societal disruption, as seen through the lens of industry, and the policy objectives of creating an effective policy response to the institutional challenges raised by this disruption and of charting a route for Finnish companies and society through this change. The scenario process in DDI serves as a tool for active dialogue and interactions among policy, research, industry, and citizens, and this shared awareness creates the foundation for the research project. The scenario method will be used throughout the project to continuously analyze the context of digital disruption and industry transformation. Meta-scenarios will be used to identify the main driving forces of the operative environment, as well as the triggers beyond the shared cognitive frames that inform changes in future development paths. Further, the created meta-scenarios will provide normative descriptions of the uncertainties related to technology development, economic and social factors, and regulative and political actions for the next 15 years.

\section{Focusing processes and triggering events in the case projects}

As described in the earlier focusing processes, social interactions and triggering events represent essential elements and outputs of scenario work. Focusing processes include events in which the different parties and their ways of thinking can be directed towards possible future paths. These enable the various actors to engage in vivid discussions and challenge possible future scenarios. Through these interactions, actors create a common understanding and a shared vision of the future. A trigger can represent an issue or event that is expected to "trigger" a chain of events or a future path to the future. Triggering events can either inspire or occur during scenario work, but in both cases, these events attract the interest of various parties to engage in the scenario work in order to prepare for the future.

In the case of the Neo-Carbon Energy project, specific scenario work has already been performed, and in the SET and the DDI, the scenario work is ongoing. The SET and NeoCarbon Energy projects are highly interlinked, since the SET builds upon the initial results of the Neo-Carbon project's scenario work (see also Fig. 2 and the discussion above). These 
two projects are more technologically oriented, with DDI taking a broader and more business-oriented perspective by focusing on multiple interconnected industries, including energy. Table 1 provides examples of focusing and triggering events for the scenario work in the Neo-Carbon Energy project, as well as for the planned and/or initial scenario work in the SET and DDI projects. The data resulting from the scenario work and the use of Delphi queries (see e.g. Glenn and Gordon, 2009) will reveal more detailed triggering events, such as abrupt changes in the energy production system.

Table 1. Illustrative examples of focusing processes and triggering events in case projects

\begin{tabular}{|c|c|c|c|}
\hline Case project & $\begin{array}{l}\text { Role of scenario } \\
\text { methods }\end{array}$ & $\begin{array}{l}\text { Focusing processes } \\
\text { utilized/to be utilized }\end{array}$ & $\begin{array}{l}\text { Triggering events } \\
\text { identified }\end{array}$ \\
\hline Neo-Carbon & $\begin{array}{l}\text { To provide insights } \\
\text { into how the future } \\
\text { RES-based energy } \\
\text { world might be } \\
\text { realized in four } \\
\text { radically different } \\
\text { transformative ways. }\end{array}$ & $\begin{array}{l}\text { Futures Clinique; } \\
\text { different foresight } \\
\text { methods (e.g. Futures } \\
\text { Window, identification } \\
\text { and impact analyses of } \\
\text { weak signals and black } \\
\text { swans, scenario } \\
\text { narratives, etc.). }\end{array}$ & $\begin{array}{l}\text { Increasing peer-to-peer } \\
\text { approaches, prosumerism, } \\
\text { ecological awareness, the } \\
\text { boom of startups with } \\
\text { open-source principles, the } \\
\text { increasing dominance of } \\
\text { technological giants, and } \\
\text { ubiquitous ICT. }\end{array}$ \\
\hline $\begin{array}{l}\text { Smart Energy } \\
\text { Transition } \\
\text { consortium } \\
\text { (SET) }\end{array}$ & $\begin{array}{l}\text { To provide an } \\
\text { understanding of the } \\
\text { rate and direction of } \\
\text { energy } \\
\text { transformation } \\
\text { towards the selected } \\
\text { scenarios }\end{array}$ & $\begin{array}{l}\text { Workshops with project } \\
\text { partners; Delphi study } \\
\text { with expert panels (tech, } \\
\text { users, policy) for } \\
\text { determining possible } \\
\text { triggering events in the } \\
\text { assumed scenarios. }\end{array}$ & $\begin{array}{l}\text { First workshop results: new } \\
\text { startups and export } \\
\text { companies, scarcity of } \\
\text { resources, ecological } \\
\text { disasters }\end{array}$ \\
\hline $\begin{array}{l}\text { Digital } \\
\text { Disruption of } \\
\text { Industry (DDI) }\end{array}$ & $\begin{array}{l}\text { To enable active } \\
\text { dialogue and } \\
\text { interactions among } \\
\text { the different actors of } \\
\text { the wider energy } \\
\text { ecosystem. }\end{array}$ & $\begin{array}{l}\text { Workshops with expert } \\
\text { panel discussions; } \\
\text { scenario work through } \\
\text { the workshops; } \\
\text { utilization of SET project } \\
\text { Delphi study results } \\
\text { applicable to this project. }\end{array}$ & $\begin{array}{l}\text { First ideas based on expert } \\
\text { discussions: the shift in the } \\
\text { Internet of Things from } \\
\text { hype to reality as a techno- } \\
\text { economic-social disruption } \\
\text { that is expected to } \\
\text { significantly influence the } \\
\text { relative competitiveness of } \\
\text { firms and nations. }\end{array}$ \\
\hline
\end{tabular}

The scenario methods in the case projects serve as tools for fostering active dialogue and interactions among the various actors involved in the energy sector (e.g. policy makers, research institutions, companies, entrepreneurs, and even citizens). First, through the scenario work in the case projects, the different stakeholders can jointly recognize the driving forces and alternative future paths of the energy sector. In practice, the interested and relevant parties are invited in workshops and participative, facilitated discussions, through which they become aware and share their views of the nature and impact of future 
developments in the energy sector, which then mobilize them to take an active role, work together, and build the necessary synergies in the planning, execution, and assessment of specific actions to respond or influence these developments. The scenario methods enable social interactions among different actors in, for example, sharing information and knowledge, building joint roadmaps, and generally co-creating effective joint responses (e.g. improving current networked processes or building new business models) to the uncertainties of energy technology development, as well as other economic, social, regulative, and political factors. The strategic research programs set by policy makers provide the incentive for and expectation that various stakeholders set up scenario processes that will enable them to learn about one another and the potential futures of the energy sector through social interaction. In this way, the scenario process can become a focal mechanism for the emergence and birth of interdependent ecosystem(s) with shared goals, visions, and purposes.

\section{Conclusions}

This paper has discussed the emergence of new ecosystems in the area of energy services from a public policy perspective. We have developed a view of scenario methods as mechanisms that help to focus the attention of potential and current actors, as well as to create visibility for triggering events that are leading future developments. In so doing, our paper answers recent calls to better understand how public policy can help the creation of business and innovation ecosystems (Clarysse et al., 2014), as well as the birth and emergence of ecosystems in general (Ritala et al., 2013). The results suggest a range of research, policy, and practical implications, which are discussed in the following.

\subsection{Research implications}

Our study contributes to the research on ecosystem emergence in general and provides implications for policy research in the field of energy services.

First, as we discussed in the beginning of the study, ecosystem emergence is among the most important, but least studied phenomena within business and innovation ecosystem literature. Our papers suggest that facilitating the emergence of ecosystems might be necessary when self-organizing is not progressing sufficiently quickly. Ecosystem coordination is often managed by a strong focal actor (see e.g. Moore, 1993; Iyer and Davenport, 2008; Isckia, 2009; Rohrbeck et al., 2009); however, in the absence of such an actor, other mechanisms become useful in enabling the emergence and growth of ecosystems. This also highlights the essential linkages between the literatures of business and innovation ecosystems and public policy research streams, such as the research on triple-helix and national innovation systems (e.g. Martin and Johnston, 1999; Etzkowitz and Leydesdorff, 2000). Since business and innovation ecosystems are complex systems with open boundaries and constant inflows and outflows (Cilliers, 2001), the interdependencies and co-evolutions between public policy and private sector actors is an issue that is relevant 
for practically any study related to emerging technologies and innovations.

Second, it has been suggested that research programs, as policy making instruments, play an important role in the creation and exchange of knowledge among participating actors (Autio et al., 2008). In this study, we have argued that scenario workshops provide the time and space for ecosystem actors to share explicit and tacit knowledge. The role of these workshops is further accentuated in situations in which businesses do not yet see concrete business opportunities and when capturing the benefits of these opportunities requires the learning and development of competences among various ecosystem actors. Especially in the highly regulated energy industry, individual actors may not have sufficient incentive to take risks, take on ecosystem leadership roles, or invest in the building of ecosystems for new energy services (Iansiti and Levien, 2004). Thus, we argue that scenario work is a usable approach to study the future of emerging energy service systems.

\subsection{Policy and practical implications}

In the Finnish new energy services context, there is no clear focal actor, single technology, or technology platform. This is also the case for many emerging technologies, which tend to face the "chicken and egg" problem. To overcome the chasms among initiative-taking, followership, and concrete actions, research programs and scenario work can be seen as especially helpful. Strategic research programs implemented by policy makers can be seen as (knowledge) platforms for connecting various ecosystem actors, since they build interdependence and require some level of coordination. Here, the recurrent interactions among knowledgeable and resourceful actors enabled by scenario work and related process can trigger the emergence of a more concrete ecosystem, which will begin to self-organize towards plausible future scenarios.

In our research, we not only illustrate the use of the scenario method as a focusing and triggering mechanism for a single strategic research program, but also show the importance of the knowledge sharing mechanisms that link different strategic research programs. Each strategic research program has a specific focus, which may not be sufficient, on its own, to turn individual research and development collaborations into a concrete ecosystem. Rather, the knowledge sharing mechanisms function as linking mechanisms that connect complementary research programs to a larger knowledge ecosystem (Clarysse et al., 2014). Yet, without the scenario method and process as a focusing and triggering mechanism, the system could suffer from inertia and fail to realize its potential. Our results highlight the potential benefits of scenario work in this regard.

\subsection{Limitations and future research directions}

This paper has limitations, especially regarding its generalizability. The case evidence presented in this paper should be treated as illustrative, since its purpose is to showcase the potential usage of scenario methods in the energy services sector context, rather than to prove cause-and-effect relationships. For instance, the SET and DDI research projects are still nascent; thus, their outcomes should be seen as plans for the actual scenario work to be 
carried out. Overall, we have revealed the very first results of the scenario work.

Future studies may build on the ideas presented on this paper in several ways. First, there is a need for studies to understand how scenario methods can facilitate ecosystem emergence. Our conceptualization of focusing processes and triggering events could serve as a foundation for conducting more data-rich case studies or broader quantitative studies. Second, more context-aware studies are needed to understand how energy sector actors, in particular, organize within ecosystems. Since many of the major global challenges are related to renewable energy, we need to know more about how business and innovation ecosystems are built around these challenges and what public policy can do to facilitate this development.

\section{References}

Aarikka-Stenroos, L., \& Sandberg, B. (2012). From new product development to commercialization through networks. Journal of Business Research, 65(2), 198-206.

Akaka, M.A., Vargo, S.L., \& Lusch, R.F. (2013). The complexity of context: A service ecosystems approach for international marketing. Journal of International Marketing, 21(4), 1-20.

Autio, E., Kanninen, S., \& Gustafsson, R. (2008). First-and second-order additionality and learning outcomes in collaborative R\&D programs. Research Policy, 37(1), 59-76.

Autio, E., \& Thomas, L.D. (2013). Innovation ecosystems: Implications for innovation management. In M. Dodgson, D.M. Gann, N. Phillips (Ed.), The Oxford Handbook of Innovation Management, 204-288, Oxford: Oxford University Press.

Bergman, J-P., Viljainen, S., Kässi, T., Partanen, J., \& Laaksonen, P. (2006). Managing the exploration of new operational and strategic activities using the scenario methodAssessing future capabilities in the field of electricity distribution industry. International Journal of Production Economics, 104, 46-61.

Cilliers, P. (2001). Boundaries, hierarchies and networks in complex systems. International Journal of Innovation Management, 5(2), 135-47.

Clarysse, B., Wright, M., Bruneel, J., \& Mahajan, A. (2014). Creating value in ecosystems: Crossing the chasm between knowledge and business ecosystems. Research Policy, 43(7), 1164-1176.

de Jouvenel, H. (2000). A brief methodological guide to scenario building. Technological Forecasting and Social Change, 65, 37-48.

Etzkowitz, H., \& Leydesdorff, L. (2000). The dynamics of innovation: from National Systems and "Mode 2" to a Triple Helix of university-industry-government relations. Research Policy, 29(2), 109-123.

Garnsey, E., \& Leong, Y.Y. (2008). Combining resource-based and evolutionary theory to explain the genesis of bio-networks. Industry and Innovation, 15(6), 669-686. 
Garnsey, E., Lorenzoni, G., \& Ferriani, S. (2008). Speciation through entrepreneurial spinoff: The Acorn-ARM story. Research Policy, 37(2), 210-224.

Gawer, A., \& Cusumano, M. A. (2014). Industry platforms and ecosystem innovation. Journal of Product Innovation Management, 31, 417-433.

Giddens, A. (1984). The Constitution of Society. Cambridge: Polity Press.

Glenn, J.C., \& Gordon, T.J. (2009). Futures Research Methodology Version 3.0. The Millennium Project.

Godet, M. (2000). The art of scenarios and strategic planning: Tools and pitfalls. Technological Forecasting and Social Change, 65, 3-22.

Hallen, B. L., \& Eisenhardt, K. M. (2012). Catalyzing strategies and efficient tie formation: How entrepreneurial firms obtain investment ties. Academy of Management Journal, $55,35-70$.

Heinonen, S., Karjalainen, J., \& Ruotsalainen, J. (2015). Towards the Third Industrial Revolution-Neo-carbon energy futures clinique I. Finland Futures Research Centre. FFRC eBook 6/2015. Accessed 30th November 2015. https://www.utu.fi/fi/yksikot/ffrc/julkaisut/e-tutu/Documents/FFRC-eBook-62015.pdf.

Heinonen, S. \& Ruotsalainen, J. (2013). Futures clinique-Method for promoting futures learning and provoking radical futures. European Journal of Futures Research, 1(7), $1-11$.

Holland, J.H. (1997). Emergence. Philosophica, 59(1), 11-40.

Iansiti, M., \& Levien, R. (2004). Strategy as ecology. Harvard Business Review, 82(3), 6881.

Isckia, T. (2009). Amazon's evolving ecosystem: A cyber-bookstore and application service provider. Canadian Journal of A dministrative Sciences, 26(4), 332-343.

Iyer, B. \& Davenport, T. H. (2008). Reverse engineering: Google's innovation machine. Harvard Business Review, A pril, 59-68.

Koivisto, V., Järventausta, P., \& Mäkinen, S. J. (2015). Role of public regulators in demand response business ecosystem-Case New York State electric power market. In the Proceedings of 12th International Conference on the European Energy Market (EEM). pp. 1-5. IEEE.

Landowski, E. (2014). Strategic research openings 2/2014. Accessed 30th November 2015. http://www.TEKES.fi/en/whats-going-on/application-schedules/strategic-researchopenings-22014/

Leten, B., Vanhaverbeke, W., Roijakkers, N., Clerix, A., \& Van Helleputte, J. (2013). IP models to orchestrate innovation ecosystems: IMEC, a public research institute in nano-electronics. California Management Review, 55, 51-64.

Lewis, J.I. \& Wiser, R.H. (2007). Fostering a renewable energy technology industry: An international comparison of wind industry policy support mechanisms. Energy Policy, 
35(3), 1844-1857.

Logenthiran, T., Srinivasan, D. \& Shun, T.Z. (2012). Demand side management in smart grid using heuristic optimization. IEEE Transactions on Smart Grid, 3(3), pp. 12441252 .

Lund, P.D. (2007). Effects of energy policies on industry expansion in renewable energy. Renewable Energy, 34(1), 53-64.

Manyika, J., Chui, M., Bughin, J., Dobbs, R., Bisson, P. \& Marrs, A. (2013). Disruptive technologies: Advances that will transform life, business, and the global economy. $\begin{array}{lll}\text { Accessed } & \text { 30th } & \text { November }\end{array}$ http://www.mckinsey.com/insights/business_technology/disruptive_technologies

Martin, B. R., \& Johnston, R. (1999). Technology foresight for wiring up the national innovation system: experiences in Britain, Australia, and New Zealand. Technological Forecasting and Social Change, 60(1), 37-54.

Masini, E., \& Vasquez, J. (2003). Scenarios as seen from a human and social perspective. Technological Forecasting and Social Change, 65, 49-66.

Midgley, G. (2008). Systems thinking, complexity and the philosophy of science. Emergence: Complexity and Organization, 10(4), 55-73.

Moller, K. \& Rajala, A. (2007). Rise of strategic nets - New modes of value creation. Industrial Marketing Management, 36(7), 895-908.

Moore, J.F. (1993). Predators and prey: A new ecology of competition. Harvard Business Review, 71(3), 75-83.

Ozcan, P.\& Eisenhardt, K.M. (2009). Origin of alliance portfolios: Entrepreneurs, network strategies, and firm performance. A cademy of Management Journal, 52, 246-279.

Pagani, G.A., \& Aiello, M. (2010). Towards a service-oriented energy market: Current state and trend. Service-Oriented Computing: ICSOC 2010 International Workshop, Revised Selected Papers, 203-209.

Pegels, A., \& Lütkenhorst, W. (2014). Is Germany's energy transition a case of successful green industrial policy? Contrasting wind and solar PV. Energy Policy, 74, 522-534.

Peltoniemi, M. (2006). Preliminary theoretical framework for the study of business ecosystems. Emergence: Complexity and Organization, 8(1), 10-19.

Penrose, E. (1995). The Theory of the Growth of the Firm. Oxford: Oxford University Press.

Rifkin, J. (2011). The third industrial revolution: How lateral power is transforming energy, the economy, and the world. London: Palgrave Macmillan.

Ritala, P., Agouridas, V., Assimakopoulos, D., \& Gies, O. (2013). Value creation and capture mechanisms in innovation ecosystems: A comparative case study. International Journal of Technology Management, 63(3-4), 244-267.

Rohrbeck, R., Hölzle, K., \& Gemünden, H. G. (2009). Opening up for competitive 
advantage-How Deutsche Telekom creates an open innovation ecosystem. $R \& D$ Management, 39(4), 420-430.

Roubelat, F. (2000). Scenario planning as a network process. Technological Forecasting and Social Change, 65, 99-112.

Schoemaker, P.J.H. (1993). Multiple scenario development: Its conceptual and behavioral foundation. Strategic Management Journal, 14, 193-213.

Schoemaker, P. J. H. (1995), Scenario planning: A tool for strategic thinking. Sloan Management Review, Winter, 25-40.

Schoemaker, P. J. H. (1997). Disciplined imagination - from scenarios to strategic options. International Studies of Management \& Organization, 27(2), 43-70.

Schwartz, P. (1996). The art of the long view - Planning for the future in an uncertain world. New York, USA: Doubleday Dell Publishing Inc.

SET (2015). Smart energy transition project description. Accessed 30th November 2015. http://www.smartenergytransition.fi/?page_id=177andlang=en.

Smith, M. Y., \& Stacey, R. (1997). Governance and cooperative networks: An adaptive systems perspective. Technological Forecasting and Social Change, 54(1), 79-94.

There (2015). There corporation solutions. Accessed 30th November 2015. http://www .therecorporation.com/solutions/.

Thomas, L.D.W., Autio, E., \& Gann, D.M. (2014). Architectural leverage: Putting platforms in context. Academy of Management Perspectives, 28(2), 198-219.

Valkokari, K. (2015). Business, innovation, and knowledge ecosystems: How they differ and how to survive and thrive within them. Technology Innovation Management Review, 5, 17-24.

van der Heijden, K., Bradfield, R., George, B., Cairns, G., \& Wright, G. (2002). The sixth sense-Accelerating organizational learning with scenarios. Chichester, UK: John Wiley and Sons, Ltd.

Wack, P. (1985a). Scenarios uncharted waters ahead. Harvard Business Review, Sept-Oct, 73-89.

Wack, P. (1985b). Scenarios: Shooting the rapids. Harvard Business Review, Nov-Dec, 139-150.

Wareham, J., Fox, P. B., \& Cano Giner, J. L. (2014). Technology ecosystem governance. Organization Science, 25, 1195-1215.

Williamson, P.J. \& De Meyer, A. (2012). Ecosystem advantage: How to successfully harness the power of partners. California Management Review, 55(1), 24-46. 